\title{
What is the Long Run Growth Rate of the East Asian Tigers
}

B. Bhaskara Rao, Artur Tamazian and Rup Singh

\section{EERI Research Paper Series No 04/2010}

ISSN: 2031-4892

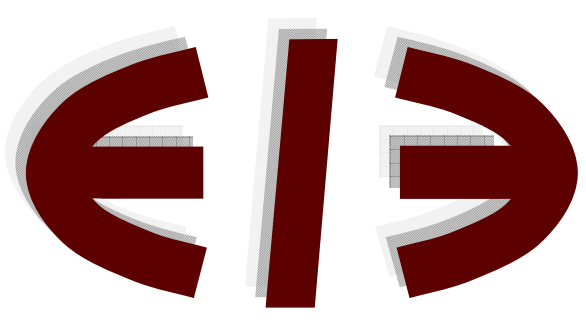

EERI

Economics and Econometrics Research Institute Avenue de Beaulieu 1160 Brussels

Belgium

Tel: +3222993523

Fax: +322 2993523

www.eeri.eu

Copyright (C 2010 by B. Bhaskara Rao, Artur Tamazian and Rup Singh 


\title{
What is the Long Run Growth Rate of the East Asian Tigers?
}

\author{
B. Bhaskara Rao \\ School of Economics and Finance \\ University of Western Sydney, Australia \\ raob123@bigpond.com \\ Artur Tamazian \\ Department of Finance \& Accounting \\ University of Santiago de Compostela, Spain \\ artur.tamazian@usc.es \\ Rup Singh \\ School of Economics \\ University of the South Pacific, Fiji \\ singh_r@usp.ac.fj
}

\begin{abstract}
New panel data estimates for the four East Asian Tigers show that the contribution of total factor productivity $(T F P)$ to growth is much higher than past estimates. An extended production function with learning by doing implies that TFP is about $3.5 \%$ and these countries will grow at this rate in the long run.
\end{abstract}

JEL: O1, N1

Keywords: Asian Tigers, Systems Dynamic GMM, Growth Accounting, Factor Accumulation as Residual. 


\section{Introduction}

This paper re-examines the decade old controversy on the East Asian miracle. To conserve space we limit to Hong Kong, Korea, Singapore and Taiwan i.e., the East Asian Tigers (EATs). We refer to excellent surveys by Seral (2000) and Jong-il Kim (2002) for bibliography. When this controversy started in early 1990s, the average GDP growth rate (1965-1990) of EATs was 8.8\% compared to UK's 3.7\% and USA's 4.0\%; see Table 1 in Jong-il Kim (2002). The controversy was on whether EATs can continue to grow at this high rate in the long run, which we may say due to the confusion between the actual high growth rate and the long run or the steady state growth rate $(S S G R)$. Since theoretical growth models imply that the $S S G R$ equals growth of total factor productivity $(T F P)$, a variety of growth accounting exercises was conducted to estimate TFP as the Solow residual. The general conclusion was much of the growth of EATs was due to factor accumulation (85\%) and not due to $T F P$. Therefore, their growth rates will tapper off eventually to equal TFP, which was estimated between $0 \%$ to $1.5 \%$.

A neglected issue in this controversy is the effect of learning by doing ( $L B D)$ on TFP. Jong-il Kim (2002) and Greiner, Semler and Gong (2005) recognise its importance by noting that developing countries go through 3 historical stages. At first $L B D$, stimulated by capital accumulation and openness to trade, play an important role in improving TFP. In the second and third stages human capital formation and expenditure on $R \& D$ are important contributors to TFP.

In this paper we extend the standard Cobb-Douglas production function to take into account some $L B D$ effects due to capital formation and trade openness $(O T)$. We also use an improved systems GMM dynamic panel data method of Arellano and Bover (1995) and Blundell and Bond (1998). Some of its advantages are: (1) it overcomes the weak instruments problem generally causing finite sample biases and (2) minimises time series problems, due to the persistence in the variables, because the model is estimated as a system in both the levels of the variables and their first differences. 
This paper is organised as follows. Specification issues are in Section 2. Empirical results are in Section 3 and Section 4 concludes.

\section{Specification ${ }^{1}$}

Some externalities are 'manna from the heaven' type and do not need additional investments by firms. In the early stages of development two such important externalities are due to $L B D$ of Arrow (1962) and $O T$. These $L B D$ effects may be due to a rapid capital accumulation through new investment in improved machines and exposure to international competition stimulates efficient methods of production. It is hard to say a priori the relative importance of these two $L B D$ effects. The Cobb-Douglas production function with constant returns can be extended to include such effects as follows.

Let a representative firm's production function, where $L B D$ effects are through the economy wide capital stock, be:

$$
\begin{aligned}
& Y_{i t}=K_{i t}^{\alpha}\left(A_{i t} L_{i t}\right)^{(1-\alpha)} \varepsilon_{i t} \\
& A_{i t}=B_{i t} K_{t}^{\varphi}
\end{aligned}
$$

where $Y$ is output, $K$ is capital, $L$ is employment and $\varepsilon_{i t}$ is an error term such that $\ln \varepsilon_{i t} \sim N\left(0, \sigma^{2}\right) . B$ stands for the stock of knowledge which depends on autonomous factors. Therefore, $\Delta \ln B$ is the rate of growth of autonomous TFP. $B$ may be constant $(\Delta \ln B=0)$ or grow at a constant autonomous rate of $g\left(B_{t}=B_{0} e^{g t}\right)$ where $B_{0}$ is the initial stock of knowledge. $\Delta \ln B$ thus captures the effects of trended variables affecting TFP. Substitutions and aggregation give the aggregate production function:

$$
Y_{t}=B_{0}^{1-\alpha} e^{g t(1-\alpha)} K_{t}^{\alpha+\varphi(1-\alpha)} L_{t}^{(1-\alpha)} \varepsilon_{t}
$$

\footnotetext{
${ }^{1}$ To conserve space we shall be brief. See Rao (2007) for details.
} 
where $\varepsilon_{t}=\left(\sqrt{\Pi_{1}^{n} \varepsilon_{i}}\right)^{1 / n}$ and $\ln \varepsilon_{t} \sim N\left(0, \sigma^{2}\right)$. Alternative assumptions about $A$ in (2) are possible.

If $O T$ has an externality through $L B D$ effects, which is important for the East Asian countries, $A$ may be specified with the two $L B D$ effects as:

$$
A_{i t}=B_{0} e^{\left(g_{1}+g_{2} O T_{t}\right) t} K_{t}^{\varphi}
$$

The aggregate production function will be

$$
Y_{t}=B_{0}^{1-\alpha} e^{(1-\alpha)\left(g_{1}+g_{2} O T\right) t} K_{t}^{(\alpha+\varphi(1-\alpha))} L_{t}^{(1-\alpha)} \varepsilon_{t}
$$

This is the same as (3) except that $g$ is now computed as $\left(g_{1}+g_{2} O T\right)$. The log-linear form of (5) where output and capital are measured in per worker terms is:

$$
\begin{aligned}
\ln y_{t}= & (1-\alpha) \ln B_{0}+(1-\alpha)\left(g_{1}+g_{2} O T_{t}\right) t \\
& +(\alpha+\varphi(1-\alpha)) \ln k_{t}+\varphi(1-\alpha) L_{t}+\ln \varepsilon_{t}
\end{aligned}
$$

where $y=(Y / L)$ and $k=(K / L)$. There is a steady state solution only when $\varphi<1$. If $\varphi \geq 1$ there is no steady state because there are no diminishing returns to $k$ and $\Delta k$ does not become zero, which is the definition of the steady state. Therefore, in the following derivation of $S S G R$ it is assumed that $\varphi<1$, and $S S G R$ implied by (6) is:

$$
S S G R=\frac{g_{1}+g_{2} O T+\varphi n}{(1-\varphi)}
$$

where $n$ is the rate of growth of labour force. The SSGR implied by (3) is a special case of (7) where $g_{2}=0$. Note that in (7) SSGR increases with respect to $g_{2}$ and $\varphi$ if $\varphi<1$. 


\section{Empirical Results}

The dynamic systems GMM method in this paper essentially requires that (6) should be estimated in the levels and first differences of the variables forms as a system. ${ }^{2}$ Estimates of (6) for the period 1972-2006 are in Table-1.

Table 1

GMM ESTIMATES OF PRODUCTION FUNCTION 1972-2006

\begin{tabular}{|c|c|c|c|}
\hline Parameters & $(1)$ & $(2)$ & $(3)$ \\
\hline Constraints & & $\varphi=0$ & $\varphi=0$ \\
& & & $\alpha=0.3$ \\
\hline Intercept & $3.90 \mathrm{E}^{-03}$ & $0.38 \mathrm{E}^{-02}$ & $0.35 \mathrm{E}^{-02}$ \\
& {$[0.00]^{*}$} & {$[0.00]^{*}$} & {$[0.00]^{*}$} \\
\hline$\alpha$ & 0.230 & 0.246 & - \\
& {$[0.01]^{*}$} & {$[0.01]^{*}$} & \\
\hline$g_{1}$ & 0.034 & 0.032 & 0.031 \\
& {$[0.00]^{*}$} & {$[0.00]$} & {$[0.00]^{*}$} \\
\hline$g_{2}$ & $5.50 \mathrm{E}^{-04}$ & $0.77 \mathrm{E}^{-03}$ & $0.59 \mathrm{E}^{-03}$ \\
& {$[0.24]$} & {$[0.05]^{*}$} & {$[0.12]$} \\
\hline$\varphi$ & $3.16 \mathrm{E}^{-03}$ & - & - \\
& {$[0.32]$} & & - \\
\hline$\rho_{1}$ & & & \\
(Level) & 0.99 & 0.99 & 0.99 \\
& {$[0.00]^{*}$} & {$[0.00]^{*}$} & {$[0.00]^{*}$} \\
\hline$R^{2}$ & & & \\
Level & 0.996 & 0.996 & 0.996 \\
Difference & 0.094 & 0.109 & 0.092 \\
\hline DW & & & \\
\hline Levels & 1.684 & 1.683 & 1.674 \\
Difference & {$[0.74]$} & {$[0.74]$} & {$[0.72]$} \\
& 1.683 & 1.682 & 1.674 \\
\hline$\chi_{I V}^{2}$ & {$[0.74]$} & {$[0.74]$} & {$[0.72]$} \\
\hline & 26.418 & 26.237 & 27.767 \\
& {$[0.19]$} & {$[0.24]$} & {$[0.23]$} \\
\hline
\end{tabular}

Notes: $p$-values are in square brackets. $*=5 \%$ and $* *=10 \%$ significance. $\chi_{I V}^{2}$ is test for over-identifying restrictions of instruments. See Data Appendix for further details.

\footnotetext{
${ }^{2}$ The random effects model (REM) is used in such dynamic panel models. However, we have conducted the Hausman test where the null is REM against the alternative of the fixed effects model. The null could not be rejected at the $5 \%$ level. The computed test statistic, with $p$-value in the square brackets is: $\chi_{3}^{2}=16.996\left[0.7 E^{-3}\right]$.
} 
In column 1 estimate of (6), with a correction for first order serial correlation in the levels equation, is given. This serial correlation coefficient is close to unity highlighting the nonsteady nature of the level variables. It is set at 0.99 to achieve convergence. ${ }^{3}$ Estimates in column (1) are good although the two $L B D$ coefficients $\varphi$ and $g_{2}$ are insignificant. Estimate of $\alpha$ (share of profits) at 0.23 , highly significant, implying that perhaps the contribution of TFP to growth has been underestimated in the previous growth accounting exercises. Estimate of $g_{1}$ implies that autonomous TFP is $3.4 \%$.

To increase the degrees of freedom and see if one and/or both $L B D$ coefficients become significant, we reestimated the equation in column (1) with 3 alternative restrictions: (a) $\varphi=0 ;$ (b) $g_{2}=0$; and (c) $\alpha=0.25$. The first of these restrictions gave marginally better results and is reported in column (2). Estimate of $\alpha$ and $g_{2}$ have slightly increased. There is a marginal improvement in $R^{2}$ of the equation in the differences. In column (3) estimates of (2) with the constraint that $\alpha$ is equal to its stylised value of one third in many growth accounting exercises is reported. This has marginally decreased $R^{2}$ of the equation in the differences and $g_{2}$ has now become insignificant even at the $10 \%$ level.

The summary statistics of these 3 estimates are close and it is hard to select the best equation. Estimates of $g_{1}$ remained virtually stable in all the 3 equations. Our subjective preference is for the estimate in column (2) because its $R^{2} s$ are marginally better. Using (2) and the sample means for $n(0.024)$ and $O T(1.47)$, the estimate of SSGR is $3.35 \%$. This has slightly increased to $3.43 \%$ when the averages for the recent 5 year period (20022006), with $n(0.014)$ and $O T$ (2.55), are used. Both estimates imply that the SSGR of EATs is well over 3\% and close to $3.5 \%$. Using the sample average growth of output of

\footnotetext{
${ }^{3}$ It may be thought that there is no need for the levels equation and the systems estimation. However, when only the equation in first differences is estimated, a standard practice in many panel data estimates of growth equations, none of the parameters were significant. This may be due to some limitations noted in the text.
} 
$6.7 \%$, the contribution of TFP is about $50 \%$. This implies that factor accumulation and TFP equally contributed to growth of the EATs.

\section{Conclusions}

In this paper we have used a more efficient systems $G M M$ technique to estimate the production function with $L B D$ effects. Our estimates showed that the share of profits is about 0.25 , which is less than the values used for ESTs in many past growth accounting exercises. Next, instead of estimating TFP as the Solow residual, it can directly be estimated with our extended production function. Consequently, it is possible to estimate the contribution of factor accumulation as a residual. This latter approach seems more convincing to us because TFP is estimated directly. Both approaches show that the contribution of TFP to growth of EATs is higher than past estimates and inspiration and precipitation seem to have played equal roles in the growth process of these countries.

Needless to say there are limitations in our paper. The two $L B D$ coefficients in column (1) were not significant and their significance is improved by imposing plausible constraints. Perhaps a larger sample may give better estimates. Our approach can be extended by identifying additional contributors to $T F P$, besides capital accumulation and $O T$. Alternative measures of $L B D$ due to capital accumulation are also possible. However, these are outside the scope of this short paper. 


\section{Data Appendix}

$\mathrm{Y}$ is real output measured in 1990 US dollars. Data are obtained from the World Bank database: http://unstats.un.org.

$\mathrm{K}$ is real stock of capital computed using data on gross fixed capital formation with the perpetual method. Depreciation rate is $4 \%$ and the initial stock of capital is 1.5 times real output in 1969. These are close to the estimates of Bosworth and Collins (2003).

$\mathrm{L}$ is labour force (or employment, whichever is available) obtained from the World Development Indicators (2007) and updated using the Asian Development Bank (ABD) database: http://www.adb.org/Documents/Books/Key Indicators/2008. Where data is unavailable, working age population (15-64 years, inclusive) are taken from World Bank Indicators (2007).

OT is openness of trade computed as the ratio exports plus imports to aggregate output. All series are in current US dollars derived from the World Bank database. 


\section{References}

Arellano, M. and S. Bond. (1998). "Dynamic panel data estimation using DPD98 for GAUSS: a guide for users.” Mimeo, Institute for Fiscal Studies, London.

Arellano, M. and O. Bover. (1995). "Another look at the instrumental variable estimation of error-components models." Journal of Econometrics, 68(1): 29-52.

Arrow, K. J., (1962) "The economic implications of learning by doing," Review of Economic Studies, 29(3): 155-173.

Bosworth, B. and Collins, S. M. (2003). "The Empirics of Growth: An Update," http://www.brookings.edu/ /media/Files/rc/papers/2003/0922globaleconomics_bosworth/ 20030307.pdf

Greiner, A., Semler, W., and Gong, G. (2004) The Forces of Economic Growth: A Time Series Perspective, Princeton, NJ: Princeton University Press.

Jong-il Kim (2002). "Total Factor Productivity Growth in East Asia: Implications for the Future," Asian Economic Papers, 1(2): 50-70.

Rao, B. B. (2007). "Estimates of the Steady State Growth Rates for Selected Asian Countries with an Endogenous Growth Framework", Presented at the $36^{\text {th }}$ Conference of Australian Economists, Hobart, Australia. http://econpapers.repec.org/paper/pramprapa/2389.htm

Sarel, M., (1995). "Growth in East Asia: What we can and what we cannot infer from it," in Productivity and Growth, Proceedings of a Conference, Andersen, P., Dwyer, J. and Gruen, D. (eds.), Sydney: Reserve Bank of Australia, pp. 237-259. 